\title{
Dynamic Adjustment in Monthly Consumer Demands for Meats
}

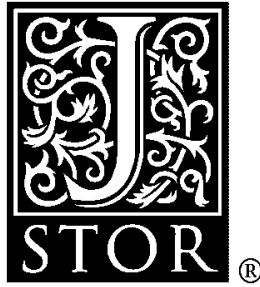

\author{
Michael K. Wohlgenant; William F. Hahn
}

American Journal of Agricultural Economics, Vol. 64, No. 3. (Aug., 1982), pp. 553-557.

Stable URL:

http://links.jstor.org/sici?sici=0002-9092\%28198208\%2964\%3A3\%3C553\%3ADAIMCD\%3E2.0.CO\%3B2-8

American Journal of Agricultural Economics is currently published by American Agricultural Economics Association.

Your use of the JSTOR archive indicates your acceptance of JSTOR's Terms and Conditions of Use, available at

http://www.jstor.org/about/terms.html. JSTOR's Terms and Conditions of Use provides, in part, that unless you have obtained prior permission, you may not download an entire issue of a journal or multiple copies of articles, and you may use content in the JSTOR archive only for your personal, non-commercial use.

Please contact the publisher regarding any further use of this work. Publisher contact information may be obtained at http://www.jstor.org/journals/aaea.html.

Each copy of any part of a JSTOR transmission must contain the same copyright notice that appears on the screen or printed page of such transmission.

The JSTOR Archive is a trusted digital repository providing for long-term preservation and access to leading academic journals and scholarly literature from around the world. The Archive is supported by libraries, scholarly societies, publishers, and foundations. It is an initiative of JSTOR, a not-for-profit organization with a mission to help the scholarly community take advantage of advances in technology. For more information regarding JSTOR, please contact support@jstor.org. 


\title{
Dynamic Adjustment in Monthly Consumer Demands for Meats
}

\author{
Michael K. Wohlgenant and William F. Hahn
}

This paper focuses on the nature of dynamic adjustment in monthly consumer demands for beef, pork, and chicken. Estimates with monthly data can differ from those with longer data periods. This is because habit formation relative to inventory adjustment decreases as the time interval decreases (Sexauer). With short time periods such as a month, inventory demand tends to dominate demand for use. If inventory demand is more elastic in the short run, the total elasticity of demand can increase as the time interval is shortened. As shown by Pasour and Schrimper, the relative importance of inventory demand with respect to the length of the adjustment period is an empirical question, and its importance can vary from commodity to commodity. This paper presents estimates of monthly consumer demands for meats and examines the role of inventories and habits on the estimated short-run demand elasticities.

\section{The State Adjustment Model and Consumer Demand for Meats}

The basic model used in this study is the Houthakker-Taylor (HT) state adjustment model. Past behavior is embodied in a state variable, encompassing both stocks held by consumers and habits formed by past consumption. The model has two equations: a short-run demand function and a stock depreciation equation.

A logical specification of the HT model for the $i$ th meat commodity is

$$
\begin{gathered}
X_{i}(t)=\alpha_{i}+\beta_{i} S_{i}(t)+\gamma_{i b} P_{b}(t)+\gamma_{i p} P_{p}(t) \\
+\gamma_{i c} P_{c}(t)+\gamma_{i m} M(t), \text { and } \\
S_{i}(t)=\frac{d S_{i}(t)}{d t}=X_{i}(t)-\delta_{i} S_{i}(t)
\end{gathered}
$$

where $i=b, p, c$ (beef, pork, chicken); $X_{i}$ is per capita demand for the $i$ th meat commodity at $t ; S_{i}$ is

Michael K. Wohlgenant is an assistant professor of economics at North Carolina State University. William F. Hahn is a graduate student in the Department of Agricultural Economics, University of California, Davis.

Journal series no. 8162 of the North Carolina Agricultural Research Service, Raleigh.

The authors gratefully acknowledge the constructive criticism of the Journal referees. At North Carolina State, D. A. Dickey, A. R. Gallant, E. C. Pasour, Jr., and several other colleagues provided many helpful comments and suggestions. the state variable of the $i$ th commodity; $P_{i}$ is the real (deflated) price of the $i$ th commodity at $t$; and $M$ is per capita real consumer income. Equation (2) specifies that stocks depreciate at a declining geometric rate over time.

If the inventory effect predominates, the coefficient, $\beta_{i}$, should be negative. That is, the larger the physical stock, the smaller will be the consumer's demand at $t$. Conversely, if habits predominate, the larger the (psychological) stock of habits and the greater will be the demand at time $t$.

With very short time periods (e.g., monthly), almost any commodity can be considered a durable which provides a stream of services over time. A major reason households hold stocks is the high opportunity cost of the consumer's shopping time (Sexauer, p. 131). Households also may hold inventories for speculative reasons (Pasour and Schrimper). For example, with a price special on pork, consumers might find it advantageous to purchase more pork now and store for later consumption.

The state variable in equation (1) is unobservable, but can be eliminated with equation (2). Since these two equations are formulated in continuous time, it is necessary to approximate them by discrete time for estimation. Following Houthakker and Taylor (chap. 1) or Phlips (chap. 6), the estimating equation for each meat commodity has the form

(3)

$$
\text { (3) } \begin{aligned}
& X_{i t}=\left[1-\frac{1}{2}\left(\beta_{i}-\delta_{i}\right)\right]^{-1}\left\{\alpha_{i} \delta_{i}+\gamma_{i b}\left(1+\frac{1}{2} \delta_{i}\right) \Delta P_{b t}\right. \\
&+\gamma_{i b} \delta_{i} P_{b t-1}+\gamma_{i p}\left(1+\frac{1}{2} \delta_{i}\right) \Delta P_{p t}+\gamma_{i p} \delta_{i} P_{p t-1} \\
&+\gamma_{i c}\left(1+\frac{1}{2} \delta_{i}\right) \Delta P_{c t}+\gamma_{i c} \delta_{i} P_{c t-1} \\
&+\gamma_{i m}\left(1+\frac{1}{2} \delta_{i}\right) \Delta M_{t}+\gamma_{i m} \delta_{i} M_{t \times 1} \\
&\left.+\left[1+\frac{1}{2}\left(\beta_{i}-\delta_{i}\right)\right] X_{i t-1}\right\}, \text { or } \\
& \text { (4) } X_{i t}= A_{i 0}+A_{i 1} \Delta P_{b t}+A_{i 2} P_{b t-1}+A_{i 3} \Delta P_{p t} \\
&+A_{i 4} P_{p t-1}+A_{i 5} \Delta P_{c t}+A_{i 6} P_{c t-1}+A_{i 7} \Delta M_{t} \\
&+A_{i 8} M_{t-1}+A_{i 9} X_{i t-1}+V_{i t},
\end{aligned}
$$

where $V_{i t}$ is a random disturbance term.

The reduced-form coefficients in (3) are restricted since the structural parameter, $\delta_{i}$, is overidentified. A unique estimate of $\delta_{i}$ is obtained if the following restrictions hold:

$$
\begin{aligned}
& A_{i 1}=A_{i 2} A_{i 7} / A_{i 8}, \\
& A_{i 3}=A_{i 4} A_{i 7} / A_{i 8}, \text { and } \\
& A_{i 5}=A_{i 6} A_{i 7} / A_{i 8} .
\end{aligned}
$$

The unique solutions of $\delta_{i}$ and $\beta_{i}$ using the reduced-form parameters are 


$$
\begin{aligned}
& \delta_{i}=1 /\left(A_{i 7} / A_{i 8}-\frac{1}{2}\right) \text { and } \\
& \beta_{i}=\delta_{i}+2\left(A_{i 9}-1\right) /\left(1+A_{i 9}\right) .
\end{aligned}
$$

Unique solutions for $\alpha_{i}, \gamma_{i b}, \gamma_{i p}, \gamma_{i c}$, and $\gamma_{i m}$ are then obtained by substituting $\delta_{i}$ and $\beta_{i}$ from (6) into $A_{i j}$ 's in (4).

The short-run derivatives of per capita demand with respect to prices and income are given by the $\gamma_{i j}$ 's and $\gamma_{i m}$ in (1). The long-run derivatives are obtained by setting each $S_{i}$ in (2) equal to zero and substituting the results into (1) to yield

$$
\begin{aligned}
X_{i} & =\frac{\alpha_{i} \delta_{i}}{\left(\delta_{i}-\beta_{i}\right)}+\frac{\gamma_{i b} \delta_{i} P_{b}}{\left(\delta_{i}-\beta_{i}\right)} \\
& +\frac{\gamma_{i p} \delta_{i} P_{p}}{\left(\delta_{i}-\beta_{i}\right)}+\frac{\gamma_{i c} \delta_{i} P_{c}}{\left(\delta_{i}-\beta_{i}\right)}+\frac{\gamma_{i m} \delta_{i} M}{\left(\delta_{i}-\beta_{i}\right)} .
\end{aligned}
$$

For $\delta_{i} \neq \beta_{i}$, the long-run demand derivatives are the price and income coefficients. If habit persistence dominates, the long-run elasticities will be larger than the short-run elasticities. Conversely, if inventory behavior is dominant, the short-run elasticities will be larger. ${ }^{1}$

\section{Empirical Analysis of Demand for Meats}

The demand equations were estimated with monthly data over the period January 1965 through June 1979. Eleven monthly intercept dummy variables were included in each regression equation to account for seasonal shifts in demand. Data on quantities and retail prices of beef and pork were obtained from the Livestock and Meat Situation, while data for chicken came from the Poultry and Egg Situation. ${ }^{2}$ Monthly data for disposable personal income are not available, so monthly personal income data from Business Statistics were used with a proportionality factor to estimate values for disposable personal income for months in between the published quarterly values. ${ }^{3}$ Quantities and income were in per capita terms, while prices and per capita income were deflated by the consumer price index.

\section{Estimation Procedure}

The main problem in estimating the HT model is serial correlation. If disturbance terms are included in the structural equations (1) and (2), then the disturbance in the estimating equation (4) will be autocorrelated. This will generate inconsistent as well as inefficient estimates since a lagged depen-

\footnotetext{
${ }^{1}$ With monthly data, these magnitudes are not strictly long-run elasticities. With quarterly and annual data we might expect to observe larger elasticities because more time is permitted for households to respond to a given price or income change.

2 The per capita quantity values were based on carcass, rather than retail, weight. The proportionality factor for converting from carcass to retail weight was relatively constant over the sample period considered.

3 The proportionality factor used in the conversion was the ratio of disposable personal income to personal income for that quarter.
}

dent variable appears in the specification. Application of Durbin's asymptotic test to the residuals of the unrestricted models indicated there was serial correlation in the beef and pork equations but none in the chicken equation. ${ }^{4}$ Autocorrelation and partial autocorrelation functions of the residuals of the beef and pork equations were calculated to identify tentatively the order of the autoregressive process of the residuals. ${ }^{5}$ Since these sample correlations are inconsistent when a lagged dependent variable appears in the specification, each model was first fitted by the instrumental variable technique suggested by Fuller (pp. 429-47). A close study of these correlation functions indicated that either a second- or third-order process would closely approximate the disturbance process of each model. Therefore, each model was first fitted with correction for third-order serial correlation, and the significance of $\rho_{3}$ was tested. In each case, the parameter, $\rho_{3}$, was insignificant. Thus, each model was fitted assuming the disturbance process was

$$
V_{t}+\rho_{1} V_{t-1}+\rho_{2} V_{t-2}=U_{t},
$$

where $U_{t}$ is independently and identically distributed with zero mean and constant variance.

Each model in (3) is nonlinear in the parameters and was estimated with Hartley's modified Gauss-Newton method. The beef and pork models also were estimated subject to the error process in (8) and the parameter restrictions in (5). Since there was no indication of serial correlation in the chicken equation, it was estimated assuming $V_{t}$ to be distributed as $U_{t}$.

Since a single-equation approach was used here, some simultaneity questions might arise. However, because meat supplies vary more than demand for meats, the demand equations can be estimated with single-equation methods without serious simultaneity problems. In addition, Heien, testing for the exogeneity of retail meat prices using the causality test of Sims, found that the data are generally consistent with this specification. ${ }^{6}$

\section{Discussion of the Econometric Results}

Estimates of the unrestricted and restricted models for the three meat commodities are reported in table 1.

For chicken meat, the unrestricted results indi-

\footnotetext{
${ }^{4}$ The Durbin- $H$ statistic could not be calculated because it entailed taking the square root of a negative number.

${ }^{s}$ It is entirely possible that the true model could be a moving average or mixed ARMA (autoregressive-moving average) process. However, it is frequently the case in applications that such processes can be approximated well by a low order autoregressive process (e.g., Gallant and Goebel). To simplify the estimation procedure, this is the approach taken in this paper.

${ }^{6}$ As Heien (p. 15) points out, considerable controversy surrounds Sim's causality test. Also, broiler results indicate independence rather than one-way causality between retail and wholesale prices. Nevertheless, the beef and pork results are consistent with the specification employed here-causality running from the wholesale to the retail level.
} 
Table 1. Estimates of the Reduced-Form Parameters of the State Adjustment Model

\begin{tabular}{|c|c|c|c|c|c|c|}
\hline \multirow{3}{*}{$\begin{array}{l}\text { Variable } \\
\text { Statistics }\end{array}$} & \multicolumn{6}{|c|}{ Model } \\
\hline & \multicolumn{2}{|c|}{ Beef, $X_{b}$} & \multicolumn{2}{|c|}{ Pork, $X_{p}$} & \multicolumn{2}{|c|}{ Chicken, $X_{c}{ }^{a}$} \\
\hline & Unrestricted & Restricted & Unrestricted & Restricted & Unrestricted & Restricted \\
\hline$\Delta P_{b}$ & $\begin{array}{c}-0.0741 \\
(0.0112)^{b}\end{array}$ & -0.0492 & $\begin{array}{c}0.0186 \\
(0.0066)\end{array}$ & 0.0509 & $\begin{array}{c}0.0078 \\
(0.0073)\end{array}$ & \\
\hline$P_{b-1}$ & $\begin{array}{c}-0.0109 \\
(0.0032)\end{array}$ & $\begin{array}{c}-0.0173 \\
(0.0033)\end{array}$ & $\begin{array}{c}0.0142 \\
(0.0020)\end{array}$ & $\begin{array}{c}0.0114 \\
(0.0017)\end{array}$ & $\begin{array}{c}0.0054 \\
(0.0026)\end{array}$ & $\begin{array}{c}0.0056 \\
(0.0025)\end{array}$ \\
\hline$\Delta \boldsymbol{P}_{p}$ & $\begin{array}{c}0.0338 \\
(0.0125)\end{array}$ & 0.0296 & $\begin{array}{c}-0.0854 \\
(0.0079)\end{array}$ & -0.0840 & $\begin{array}{c}0.0015 \\
(0.0090)\end{array}$ & \\
\hline$P_{p-1}$ & $\begin{array}{c}0.0149 \\
(0.0033)\end{array}$ & $\begin{array}{c}0.0104 \\
(0.0033)\end{array}$ & $\begin{array}{c}-0.0311 \\
(0.0034)\end{array}$ & $\begin{array}{r}-0.0307 \\
(0.0031)\end{array}$ & $\begin{array}{c}0.0011 \\
(0.0028)\end{array}$ & $\begin{array}{c}0.0009 \\
(0.0027)\end{array}$ \\
\hline$\Delta P_{c}$ & $\begin{array}{c}-0.0331 \\
(0.0141)\end{array}$ & -0.0484 & $\begin{array}{c}0.0209 \\
(0.0084)\end{array}$ & 0.0189 & $\begin{array}{c}-0.0147 \\
(0.0082)\end{array}$ & \\
\hline$P_{c-1}$ & $\begin{array}{c}-0.0378 \\
(0.0068)\end{array}$ & $\begin{array}{c}-0.0170 \\
(0.0053)\end{array}$ & $\begin{array}{c}0.0045 \\
(0.0042)\end{array}$ & $\begin{array}{c}0.0069 \\
(0.0029)\end{array}$ & $\begin{array}{c}-0.0228 \\
(0.0063)\end{array}$ & $\begin{array}{r}-0.0230 \\
(0.0063)\end{array}$ \\
\hline$\Delta M$ & $\begin{array}{l}12.300 \\
(8.7884)\end{array}$ & $\begin{array}{l}18.851 \\
(5.1933)\end{array}$ & $\begin{array}{c}5.5273 \\
(5.2553)\end{array}$ & $\begin{array}{c}5.2098 \\
(1.7046)\end{array}$ & $\begin{array}{c}2.8347 \\
(4.6096)\end{array}$ & \\
\hline$M_{t-1}$ & $\begin{array}{c}3.8418 \\
(1.6206)\end{array}$ & $\begin{array}{c}6.6237 \\
(1.6831)\end{array}$ & $\begin{array}{c}1.4750 \\
(0.7789)\end{array}$ & $\begin{array}{c}1.9035 \\
(0.6775)\end{array}$ & $\begin{array}{l}12.1047 \\
(1.5136)\end{array}$ & $\begin{array}{l}12.091 \\
(1.4943)\end{array}$ \\
\hline$X_{i-1}$ & $\begin{array}{c}0.6162 \\
(0.0448)\end{array}$ & $\begin{array}{c}0.6097 \\
(0.0508)\end{array}$ & $\begin{array}{c}0.4954 \\
(0.0392)\end{array}$ & $\begin{array}{c}0.5023 \\
(0.0399)\end{array}$ & $\begin{array}{c}0.0660 \\
(0.0821)\end{array}$ & $\begin{array}{c}0.0682 \\
(0.0807)\end{array}$ \\
\hline$\rho_{2}$ & $\begin{array}{c}0.5611 \\
(0.0743) \\
0.2947 \\
(0.0639)\end{array}$ & $\begin{array}{c}0.4634 \\
(0.0723) \\
0.2311 \\
(0.0641)\end{array}$ & $\begin{array}{c}0.6623 \\
(0.0757) \\
0.3359 \\
(0.0647)\end{array}$ & $\begin{array}{c}0.6259 \\
(0.0760) \\
0.3083 \\
(0.0653)\end{array}$ & & \\
\hline$R^{2}$ & 0.80 & 0.78 & 0.84 & 0.83 & 0.84 & 0.84 \\
\hline$\sigma^{2}$ & 0.1406 & 0.1528 & 0.0541 & 0.0558 & 0.0350 & 0.0357 \\
\hline
\end{tabular}

Note: $X_{i}(i=b, p, c)$ is per capita quantity of $i$ th meat commodity purchased (lb./person); $P_{i}$ is deflated price of the $i$ th meat commodity ( $\mathrm{a} / \mathrm{lb}$.); and $M$ is per capita deflated disposable personal income $(\$ 1000 /$ person); monthly intercept values are not reported but can be obtained from the senior author.

a Parameter estimates of the flow adjustment model where coefficient estimates pertain to average price and income levels.

b Values in parentheses are the estimated standard errors.

cate that the estimated stock depreciation parameter, $\delta$, is outside the range required for stability $(|\delta|$ $<2$ ). Houthakker and Taylor (chap. 2) encountered this situation, and showed that when $1 / \delta=0$, the estimating equation reduces to a discrete version of the continuous time-flow adjustment model. Following Houthakker and Taylor (chap. 2), the discrete version of this model can be written as

$$
\text { (9) } \begin{aligned}
X_{c t}=[\Psi / & \left.\left(1+\frac{1}{2} \Psi\right)\right]\left(\alpha_{c}+\gamma_{c b} \bar{P}_{b t}+\gamma_{c p} \bar{P}_{p t}\right. \\
& \left.+\gamma_{c c} \bar{P}_{c t}+\gamma_{c m} \bar{M}_{t}\right) \\
& +\left[\left(1-\frac{1}{2} \Psi\right) /\left(1+\frac{1}{2} \Psi\right)\right] X_{c t-1}+V_{c t},
\end{aligned}
$$

where $\Psi$ is the coefficient of adjustment parameter $(\Psi>0), \bar{P}_{b t}=\frac{1}{2}\left(P_{b t}+P_{b t-1}\right)$, etc. This specification is identical to equation (3) when the restrictions in (5) hold and $A_{c 7} / A_{c 8}=\frac{1}{2}$. In this case, however, $\gamma_{i j}$ 's are long-run rather than short-run price and income slopes. Estimates of equation (9) for chicken are in the last two columns of table 1 .

Unrestricted and restricted estimates of each model are reported in table 1 . For each commodity, the restricted model is tested against the unrestricted with the likelihood ratio test (Gallant). This test statistic is based on a minus twice the logarithm of the likelihood ratio, which follows the chisquared distribution with degrees of freedom equal to the number of independent restrictions tested. It is computed as $(n) \ln \left(\tilde{\sigma}^{2} / \hat{\sigma}^{2}\right)$, where $n$ is the number of observations (171 for beef, pork; 173 for chicken), $\tilde{\sigma}^{2}$ is the estimated disturbance variance under the null hypothesis, and $\hat{\sigma}^{2}$ is the estimated disturbance variance under the alternative hypothesis. The computed values for beef, pork, and chicken are $13.97,6.22$, and 1.73 , respectively. For beef and pork this statistic has 3 degrees of freedom, and for chicken it has 4 degrees of freedom. The critical value for beef and pork at the $5 \%$ significance level is 7.81, while the critical value for chicken is 9.49 . Thus, we believe that the pork and chicken data are consistent with the hypothesized demand specifications. However, the test statistic for beef is larger than the critical value, causing us to doubt that the state adjustment model is adequate.

Structural estimates of the state adjustment model for beef and pork, and the flow adjustment model for chicken are presented in table 2 . For beef 
Table 2. Structural Parameter Estimates of the State and Flow Adjustment Models

\begin{tabular}{lccccccc}
\hline & \multicolumn{7}{c}{ Structural Parameter Estimate } \\
\cline { 2 - 8 } Commodity & $\delta$ & $\beta$ & $\Psi$ & $\gamma_{b}$ & $\gamma_{p}$ & $\gamma_{c}$ & $\gamma_{m}$ \\
\hline \multirow{2}{*}{ Beef } & 0.4263 & -0.0586 & & -0.0504 & 0.0303 & -0.0495 & 19.3048 \\
& $(0.1077)$ & $(0.1023)$ & & $(0.0104)$ & $(0.0085)$ & $(0.0156)$ & $(5.9918)$ \\
Pork & 0.4471 & -0.2155 & & 0.0339 & -0.0914 & 0.0205 & 5.6679 \\
& $(0.0601)$ & $(0.0662)$ & & $(0.0053)$ & $(0.0106)$ & $(0.0081)$ & $(1.9120)$ \\
Chicken & & & 1.7500 & 0.0060 & 0.0010 & -0.0246 & 12.9545 \\
& & & $(0.1415)$ & $(0.0099)$ & $(0.0061)$ & $(0.0362)$ & $(17.8299)$ \\
\hline
\end{tabular}

Note: The structural parameter estimates for beef and pork correspond to the state adjustment model in equations (1) and (2), while the structural parameter estimates for chicken correspond to the flow adjustment model in equation (9). Standard errors of the parameter estimates (the values in parentheses) were calculated from formulas for the asymptotic variance for a function of random variables (e.g., Goldberger, p. 124).

and pork, the depreciation coefficient, $\delta$, suggests stability. Both own-price parameters are negative, and both income parameters are positive. The results indicate that beef and pork are substitutes. However, the relationship between chicken and the other two commodities is less clear.

For both commodities the monthly stock adjustment coefficient, $\beta$, is negative, indicating that inventory behavior predominates. For pork, the stock coefficient estimate is highly significant, indicating that inventory adjustment is an important short-run feature of consumer behavior.

The stock adjustment coefficient estimate for beef, although negative, is insignificant. Since the state adjustment model was statistically rejected as well, we doubt the adequacy of this specification for beef. One reason this model might be too restrictive is that the consumption data also include lower quality, manufacturing beef, an important commodity in fast food chains. Since beef demand in fast food outlets is likely quite different from choice beef demand for home consumption, it is not surprising that the state adjustment is too restrictive for all beef purchased, and the inventory effect is found to be less important for beef than pork. More detailed analysis is required before any firm conclusions can be drawn about monthly purchase behavior for beef.

A popular model in dynamic analysis of consumer demand is Nerlove's partial adjustment model. For the $i$ th meat commodity, this model is

$$
\begin{aligned}
X_{i t}-\eta\left(\alpha_{i}+\gamma_{i b} P_{b t}+\gamma_{i p} P_{p t}\right. & \\
& \left.+\gamma_{i c} P_{c t}+\gamma_{i m} M_{t}\right)+(1-\eta) X_{i t-1},
\end{aligned}
$$

where $\eta$ is the partial adjustment parameter. Observe that this specification is the same as equation (3) when the restrictions in (5) hold and $A_{i 7}=A_{i 8}$. This model is, therefore, appropriate if $\delta=2$ (Houthakker and Taylor, chap. 2). The calculated $t$-values for beef and pork under the null hypothesis (Ho: $\delta=2$ ) are -14.61 and -7.44 , respectively. Thus, in each case, we decisively reject the partial adjustment model in favor of the state adjustment model. ${ }^{7}$

\footnotetext{
${ }^{7}$ We have not tested for the partial adjustment model in chicken since the flow adjustment model already constrains the parameter as $1 / \delta=0$
}

\begin{tabular}{|c|c|c|c|c|}
\hline & \multicolumn{4}{|c|}{ Elasticity with Respect to } \\
\hline & Price of Beef & Price of Pork & Price of Chicken & Per Capita Income \\
\hline \multicolumn{5}{|l|}{ Beef } \\
\hline 1. Short run & -0.49 & 0.23 & -0.20 & 0.51 \\
\hline 2. Long run & -0.43 & 0.20 & -0.17 & 0.45 \\
\hline \multicolumn{5}{|l|}{ Pork } \\
\hline 1. Short run & 0.60 & -1.25 & 0.15 & 0.27 \\
\hline 2. Long run & 0.40 & -0.84 & 0.10 & 0.18 \\
\hline \multicolumn{5}{|l|}{ Chicken } \\
\hline 1. Short run & 0.08 & 0.0 & -0.14 & 0.49 \\
\hline 2. Long run & 0.18 & 0.02 & -0.30 & 1.06 \\
\hline
\end{tabular}

Table 3. Price and Income Elasticities of the Dynamic Models of Demands for Meats

Note: The elasticities are computed at the sample means. The values of per capita purchases for beef, pork, and chicken are $9.43,5.18$, and 3.09. The mean prices for these three meats are $91.27,71.06$, and 37.29. Mean per capita income is 0.25 . 


\section{Implications}

Price and income elasticities are presented in table 3. For beef and pork, where inventory behavior predominates, the short-run price and income elasticities are larger in absolute value than their longrun values. The response to either a change in price or income is more elastic in the short run than the long run because households can vary their stocks as well as their consumption. With pork, the ownprice elasticities indicate that demand is relatively price elastic in the short run but relatively inelastic when enough time has elapsed for full adjustment to occur. The results indicate more short-run price responsiveness for pork, but about the same for beef as in past studies using monthly data (Myers and Havlicek). For chicken, we find that demand is more elastic in the long run than in the short run. The long-run income elasticity of demand is larger than expected. However the standard error of the income variable is quite large, table 2 .

These results have implications for short-run retail price behavior. Many believe that retail prices remain relatively stable in the short run because of retail pricing policies (e.g., Heien). However, the beef and pork results indicate that household inventory adjustment may be important. The predominance of inventory behavior means that demand is more price elastic within a given month than over a longer period. Thus, we should observe less shortrun price variability for a given change in supply because demand is relatively more elastic.

In summary, this analysis emphasizes the role of time on measured demand elasticities of meats. For pork, the results indicate inventory adjustment dominates consumption habits, implying demand is more elastic when monthly data are used. The results for chicken are consistent with the flow adjustment model, suggesting the predominance of consumption habits and less demand responsiveness in the short run. Although the beef demand estimates indicate inventory adjustment predominates, this effect is not significant, and the state adjustment model seems too restrictive. Perhaps more refined data and modeling techniques can give additional insight into monthly demand for this commodity.

[Received June 1981; revision accepted January 1982.]

\section{References}

Durbin, J. "Testing for Serial Correlation in LeastSquares Regression When Some of the Regressors Are Lagged Dependent Variables." Econometrica 38(1970):410-21.

Fuller, W. A.Introduction to Statistical Time Series. New York: John Wiley \& Sons, 1976.

Gallant, A. R. "Testing a Subset of the Parameters of a Nonlinear Regression Model.' J. Amer. Statist. Assoc. 70(1975):927-32.

Gallant, A. R., and J. J. Goebel. "Nonlinear Regression with Autocorrelated Errors." J. Amer. Statist. Assoc. 71(1976):961-67.

Goldberger, A. S. Econometric Theory. New York: John Wiley \& Sons, 1964.

Hartley, H. O. "The Modified Gauss-Newton Method for the Fitting of Nonlinear Regression Functions by Least Squares." Technometrics 3(1961):269-80.

Heien, D. M. "Markup Pricing in a Dynamic Model of the Food Industry." Amer. J. Agr. Econ. 62(1980):1018.

Houthakker, H. S., and L. D. Taylor. Consumer Demand in the United States: Analysis and Projections. Cambridge MA: Harvard University Press, 1970.

Myers, L. H., and J. Havlicek. "Monthly Price Structure of the U.S. Beef, Pork, and Broiler Markets." Quantitative Models of Commodity Markets, ed. W. C. Labys. Cambridge MA: Ballinger Publishing Co., 1975.

Pasour, E. C., and R. A. Schrimper. "The Effect of Length of Run on Measured Demand Elasticities." $J$. Farm Econ. 47(1965):774-88.

Phlips, L. Applied Consumption Analysis. Amsterdam: North-Holland Publishing Co., 1974.

Sexauer, B. "The Role of Habits and Stocks in Consumer Expenditure." Quart. J. Econ. 91(1977):127-42.

U.S. Department of Agriculture. Livestock and Meat Situation. Washington DC, bimonthly, selected issues.

Poultry and Egg Situation. Washington DC, bimonthly, selected issues.

U.S. Department of Commerce. Business Statistics. Washington DC, annual, selected issues. 
http://www.jstor.org

\title{
LINKED CITATIONS
}

- Page 1 of 2 -

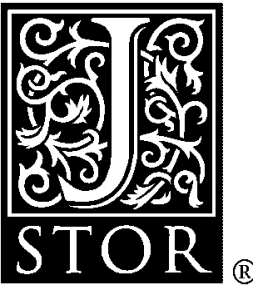

You have printed the following article:

Dynamic Adjustment in Monthly Consumer Demands for Meats

Michael K. Wohlgenant; William F. Hahn

American Journal of Agricultural Economics, Vol. 64, No. 3. (Aug., 1982), pp. 553-557.

Stable URL:

http://links.jstor.org/sici?sici=0002-9092\%28198208\%2964\%3A3\%3C553\%3ADAIMCD\%3E2.0.CO\%3B2-8

This article references the following linked citations. If you are trying to access articles from an off-campus location, you may be required to first logon via your library web site to access JSTOR. Please visit your library's website or contact a librarian to learn about options for remote access to JSTOR.

\section{[Footnotes]}

\author{
${ }^{6}$ Markup Pricing in a Dynamic Model of the Food Industry \\ Dale M. Heien \\ American Journal of Agricultural Economics, Vol. 62, No. 1. (Feb., 1980), pp. 10-18. \\ Stable URL: \\ http://links.jstor.org/sici?sici=0002-9092\%28198002\%2962\%3A1\%3C10\%3AMPIADM\%3E2.0.CO\%3B2-H
}

\section{References}

The ET Interview: Arthur S. Goldberger

Nicholas M. Kiefer; Arthur S. Goldberger

Econometric Theory, Vol. 5, No. 1. (Apr., 1989), pp. 133-160.

Stable URL:

http://links.jstor.org/sici?sici=0266-4666\%28198904\%295\%3A1\%3C133\%3ATEIASG\%3E2.0.CO\%3B2-T

The Modified Gauss-Newton Method for the Fitting of Non-Linear Regression Functions by Least Squares

H. O. Hartley

Technometrics, Vol. 3, No. 2. (May, 1961), pp. 269-280.

Stable URL:

http://links.jstor.org/sici?sici=0040-1706\%28196105\%293\%3A2\%3C269\%3ATMGMFT\%3E2.0.CO\%3B2-0

NOTE: The reference numbering from the original has been maintained in this citation list. 
http://www.jstor.org

\section{LINKED CITATIONS \\ - Page 2 of 2 -}

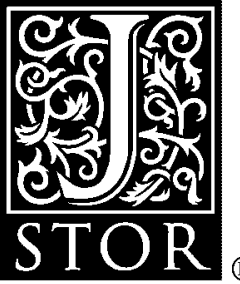

\section{Markup Pricing in a Dynamic Model of the Food Industry}

Dale M. Heien

American Journal of Agricultural Economics, Vol. 62, No. 1. (Feb., 1980), pp. 10-18.

Stable URL:

http://links.jstor.org/sici?sici=0002-9092\%28198002\%2962\%3A1\%3C10\%3AMPIADM\%3E2.0.CO\%3B2-H

NOTE: The reference numbering from the original has been maintained in this citation list. 